\title{
The syntax, semantics and pragmatics of 'optional' wh-in situ in Greek
}

\author{
Christos Vlachos \\ University of Patras, Patras, Greece \\ cvlachos@upatras.gr \\ Michalis Chiou \\ Athens Metropolitan College, Athens, Greece \\ mchiou@mitropolitiko.edu.gr
}

\begin{abstract}
Building on the relevant literature, this paper provides an up-to-now missing overarching approach to 'optional' $w h$-in situ questions in Greek, by arguing that some properties of $w h$-in situ are computed at the interface between syntax and semantics, other properties relate to the syntax-pragmatics interface, and yet others are derived at the interface between PF and pragmatics. Wh-in situ is not semantically (hence, syntactically) equivalent to $w$-fronting, with the latter being the default strategy of Greek on empirical grounds. Wh-in situ assumes distinct syntax and semantics, while its pragmatics is computed partly by the way it is associated to the discourse, and partly by intonation.
\end{abstract}

\section{Keywords}

wh-in situ - wh-fronting - syntax - semantics - pragmatics - intonation

\section{Introduction}

As has extensively been discussed in the literature on wh-questions in Modern Greek (henceforth, Greek), a matrix $w h$-question with a single $w h$-interrogative phrase may implement one of the two strategies in (1) (see, e.g., Sinopoulou 
2009, 2019; Vlachos 2010, 2012, 2014, 2019; Roussou, Vlachos \& Papazachariou 2013; Chiou \& Vlachos 2017). In passing, notice that, in the English translation of the gloss (1b), the wh-phrase appears in situ with an intended non-echo reading. This is a practice we maintain throughout, and is just for the purposes of presentation, without any implication about English optional $w h$-in situ questions (for a discussion of these questions in English, see Pires \& Taylor 2007).

(1) a. Pjon idhes?
who.ACC saw.3sG
'Who did you see?'

b. Idhes pjon?

saw.3SG who.ACC

'You saw who?'

c. Idha ton Jani.

saw.1SG the.ACC John.ACC

'I saw John.'

In (1a), the wh-phrase pjon surfaces at the 'front' of the rest of the clause, while in (1b), the wh-phrase appears 'in situ', i.e., in its canonical argument position, where a non-interrogative object of the verb would typically appear, as in (1c).

The literature so far has examined several properties of $w h$-in situ questions like (1b), in comparison with their wh-movement counterparts such as (1a), vis-à-vis syntax, semantics, prosody, and discourse. However, none of these accounts has put all these properties together under a single approach. This is the task we take up in the present paper: By putting together several pieces of empirical evidence, most of which is already presented in the literature, we offer an overarching approach to $w h$-in situ questions like (1b), which distinguishes them from their $w h$-fronting analogues like (1a), across syntax, semantics, and pragmatics.

The discussion unfolds as follows. In Section 2, we examine various properties of $w h$-in situ questions, in comparison with their $w h$-movement counterparts, with respect to distribution, intonation and interpretation. These facts underpin the core part of the analysis elaborated in sections 3 and 4, where we place the various properties of $w h$-in situ at the syntax-semantics and the syntax-pragmatics interfaces respectively. A supplementary aspect of the analysis is given in Section 5 , where we return to an interpretational effect of $w h$-in 
situ (already examined in Section 2), which we attribute to the way intonation $(\mathrm{PF})$ affects pragmatics. Section 6 concludes the discussion.

\section{$2 \quad$ The $w h$-in situ pattern}

In this section, we group together a range of empirical evidence, already discussed in the literature cited previously, which exemplifies most vividly the $w h$-in situ pattern, in comparison with the $w h$-fronting one. These data span three distinct but interrelated domains of grammar: Distribution (section 2.1), prosody (section 2.2), and interpretation (section 2.3).

\subsection{Distribution}

To begin with the evidence from distribution, Kotzoglou (2006) (among others; see references cited therein) notes that $w$ h-fronting questions obligatorily trigger inversion of the clausal S(ubject) over the $\mathrm{V}(\mathrm{erb})$, leading to a vs order. Consider (2).

(2) a. I Maria aghapai ton Ilia. the.NOM Maria.Nom love.3SG the.ACC Ilias.ACC 'Maria loves Ilias.'

b. Pjon aghapai $i \quad$ Maria?

who.ACc love.3SG the.NOM Maria.ACC 'Who does Maria love?'

c. *Pjon $i \quad$ Maria aghapai? who.ACC the.Nom Maria.nOM love.3sG 'Who does Maria love?' (Kotzoglou 2006: 95, (3a), (3b) \& (3d) respectively)

The declarative (2a) features a typical sv order, where the subject $i$ Maria 'the Mary' surfaces before the verb aghapai 'loves'. However, in the wh-fronting question (2b), V must precede $\mathrm{S}$, as is obvious by the ungrammatical whfronting counterpart $(2 \mathrm{c})$, which assumes the declarative SV order of (2a). In short, (2) shows that $\mathrm{S}$ must not intervene between the fronted $w h$-phrase and $\mathrm{V}$. 
The $w h$-in situ pattern is clearly distinct, as (3) shows (see Vlachos 2019 for a recent discussion).
(3) a. $I$
Maria
aghapai pjon?
the.NOM Maria.NOM love.3SG who.ACC
'Maria loves who?'
b. (?)Aghapai $i \quad$ Maria pjon?
love.3SG the.NOM Maria.NOM who.ACC
'Maria loves who?'

The $w h$-in situ question in (3a) assumes the declarative order of (2a), and not the interrogative order of the $w h$-fronting question in (2b). In fact, in $w h$-in situ, $S$ may intervene between $V$ and the $w h$-phrase, as shown in ( $3 b)$. Crucially, this intervention may lead to a drop in acceptability (although the jury is still out about this judgement; hence, the question mark within parentheses), but not to a downright ungrammatical result, as is the case with the corresponding $w h$ fronting question in (2c).

Turning to embedded environments, again, the pattern between the two strategies differs substantially, as is expected after all. More precisely, unlike a $w h$-fronting question, a $w h$-in situ one cannot serve as the complement of a rogative predicate; that is, a predicate that selects interrogative complements, such as wonder, ask, etc. (for the typical classification of predicates according to the type of complement they select, see Lahiri 2002):

\section{(4) a. Rotisan ti ipe. ask.3PL what said.3SG \\ 'They asked what s/he said.'}
b. *Rotisan ipe $\quad t i$. ask.3PL said.3SG what ‘*They asked said what.'

The $w h$-fronting question (4a) may satisfy the selectional requirements of rotisan 'asked', but the $w h$-in situ counterpart cannot do so.

In fact, the only way that the $w h$-in situ question can serve as the complement of a matrix predicate is if the embedded complementizer - that is, the complementizer introducing the $w h$-in situ question-is independently filled by a suitable lexical item (by 'independently' we mean by a lexical item distinct from the $w h$-in situ phrase). Interestingly, if this requirement is satisfied, 
a wh-in situ phrase may surface in the complement clause of any type of predicate (provided, of course, that the predicate selects clausal complements) as (5) demonstrates.

(5) a. Pistevis oti ipe ti?
believe.2SG that said.3SG what
'You believe that s/he said what?'

b. Dhen kseris an/oti ipe ti? NEG know.2SG if/that said.3sg what 'You don't know if/that s/he said what?'

c. Rotises an ipe ti? ask.2SG if said.3SG what 'You asked if s/he said what?'

In (5a), the predicate is uninterrogative, typically selecting declarative complements. A $w h$-in situ question is licit as long as the complementizer oti 'that' is realized. Likewise, kseris 'know' in ( 5 b) belongs to the responsive class of predicates, which may select either interrogative or declarative complements (for a discussion of this class of predicates in Greek, see Roussou 2010). A wh-in situ question is grammatical with such predicates, provided that the appropriate complementizer an 'if' or oti' 'that' is realized. Compared to (4b), (5c) says that a $w h$-in situ question is grammatical with rogative predicates, if an interrogative complementizer (here, an 'if') is present.

Continuing with embedded environments, a long-standing observation about $w h$-fronting questions in Greek is that a wh-phrase may not escape a strong-island (for discussions of strong-islands, see Ross 1967; Szabolcsi 2006; for the typical islandhood pattern of fronting $w h$-questions in Greek, see Horrocks \& Stavrou 1987; Kotzoglou 2005, among others). This is shown in (6), where $t i$ 'what' crosses an adjunct clause, as shown by the relevant bracketing (henceforth, copies of extracted items will be enclosed in angle brackets):

$$
\begin{aligned}
& \left.{ }^{*} \mathrm{Ti} \text { se timorise [epidhi ipes }\langle t i\rangle\right] \\
& \text { what you.CL punish.3Sg because said.2SG } \\
& \text { '*What did s/he punish you because you said?' (Vlachos 2012: 24, (5)) }
\end{aligned}
$$

On the other hand, a $w h$-in situ phrase inside an adjunct clause leads to a grammatical result, as shown in (7), which is comparable to (6) above: 


\section{(7) Se timorise [epidhi ipes ti]} you.CL punish.3sg because said.2SG what

'S/he punished you because you said what?' (modelled on Vlachos 2012: $24,(5))$

A final piece of evidence from distribution which shows that $w h$-in situ questions assume a strategy distinct from their wh-fronting counterparts comes from considerations revolving around scope. On grounds independent to Greek wh-questions, Starke (2001) observes that a $w h$-fronting adjunct in French may facilitate one of two readings: an event-related interpretation which is associated with the clausal predicate only, or a fact-related reading which concerns the entire proposition. Vlachos (2012) shows that Starke's (2001) observation extends to Greek $w h$-fronting questions, as in (8):
Ke pos efjes toso noris apo to parti?
and how left.2SG such early from the party
i. 'How did you leave the party that early?'
ii. 'How come you left the party that early?' (Vlachos 2012: 62, (15a))

The $w$-adjunct pos 'how' in (10) may have two distinct readings. In the reading given in (i), the $w h$-adjunct is understood as a manner adverb: The question is about 'the way' one left the party, in which case the adjunct is associated only with the event denoted by the predicate efjes 'left'. In the reading shown in (ii), the $w h$-adjunct translates to a reason adverb: The question is about 'the fact' one left the party, in which case the adjunct is related to the entire proposition. In more structural terms, and anticipating a more elaborate syntactic analysis in section (3), the two readings reflect two distinct scope-talking positions that the $w h$-adjunct may occupy: the fact-related interpretation arises from the 'high', so to speak, scope of the $w h$-adjunct, presumably encoded in the clausal left periphery. The event-related reading derives from the 'low' scope of the whadjunct, apparently restricted to the area surrounding the predicate. ${ }^{1}$

1 A reviewer correctly points out that if ke follows pos, as in (i), then the high reading is obligatory, while the low reading becomes downright ungrammatical.

(i) Pos ke efijes toso noris apo to parti?

how and left.2sG that early from the parti

a. *How did you leave the party that early?

b. How come you left the party that early?

We agree with the reviewer that pos ke configurations in cases like (i) might involve some kind of ellipsis (e.g. pos etixe/sinevi ke 'how come it happened'), and from this perspective would not constitute a minimal pair with the ke pos arrangements presently examined. This is why 
On the other hand, unlike $w h$-fronting, $w h$-in situ adjuncts may yield only the event-related reading, as in (9i), while the fact-related interpretation is infelicitous to context (hereafter, 'infelicity to context' is indicated with the sign '\#'):

(9) Ke efijes toso noris apo to parti pos? and left.2SG such early from the party how

i. 'How did you leave the party that early?'

ii. \#'How come you left the party that early?' (Vlachos 2012: 62, (15b))

In short, while a $w h$-fronting adjunct may scope either 'high' or 'low' in the clause (cf., (8)), a wh-in situ adjunct may scope only 'low' (cf., (9)).

Corroborating evidence for the 'low' scope of $w h$-in situ adjuncts comes from the licensing of $\mathrm{P}$ (olarity) $\mathrm{I}($ tems $)$. In particular, while $w h$-fronting facilitates PIlicensing (Giannakidou 1998), Sinopoulou (2009) shows that wh-in situ does not license PIs, as exemplified by the minimal pair in (10):

(10) a. Pjos exi pai pote stin Afriki?

who.NOM have.3Sg go.3sg ever to-the Afrika.ACC

'Who has ever been to Africa?'

b. *Exi pai pote stin Afriki pjos?

have.3SG go.3SG ever to-the Afrika.ACC who.NOM

'Who has ever been to Africa?' (Sinopoulou 2009, (44a) \& (44b) respectively)

In (10a), the fronted pjos 'who' licenses the PI pote 'ever', but in (10b), the in situ counterpart does not; hence, the ungrammaticality. Next, let us turn to evidence from prosody.

\subsection{Prosody}

Arvaniti (2001) has extensively studied and described the intonation structure of $w h$-fronting questions in Greek, as a sequence of $\mathrm{L}^{*}+\mathrm{H} \mathrm{L}-! \mathrm{H} \%$, where $\mathrm{L}^{*}+\mathrm{H}$ is the pitch accent, L- is the phrase accent, and $! \mathrm{H} \%$ is boundary tone. This pitch accent appears on the wh-phrase, at the beginning of the wh-question, and is either high $\left(\mathrm{H}^{*}\right)$, if the utterance starts immediately with a monosyl-

we do not consider cases like (i) in the present paper, and we refer the interested reader to Vlachos (2012) for a first comparison of the 'ke pos vs. pos ke' pattern in the context of whquestions. 
labic stressed $w h$-word, or rising $(\mathrm{L}+\mathrm{H})$, if the beginning of the utterance is another word, which is unstressed and surfaces before the $w h$-element (see also Arvaniti \& Ladd 2009). Typical instances of the latter case are prepositional phrases that head $w h$-phrases, like apo $p u$ 'from where', whereby the preposition apo 'from' phonetically precedes the adverb $p u$. The phrase accent is a Ltone, which is realized either phonetically, if there is not enough segmental material, or on a lexically stressed syllable following the $w h$-phrase, when the $w h$-question is not a short one. Finally, there is always a rising at the final syllable of the utterance, therefore a $\mathrm{H} \%$ boundary tone.

In Vlachos's (2012) experimental study of the intonation of $w$ h-fronting questions (as well as of $w$ h-in situ ones, which enter the discussion at the end), the relevant findings perfectly replicate Arvaniti's (2001) pattern. This is shown in (11b), which is the melody of the $w h$-fronting question in (11a) (see also Roussou, Vlachos \& Papazachariou 2013 for a discussion of these patterns along the same line of reasoning).

(11) a. Ke pja nomizis oti idhe? and who.ACC think.2SG that saw.3sG 'And who do you think that s/he saw?'

b.

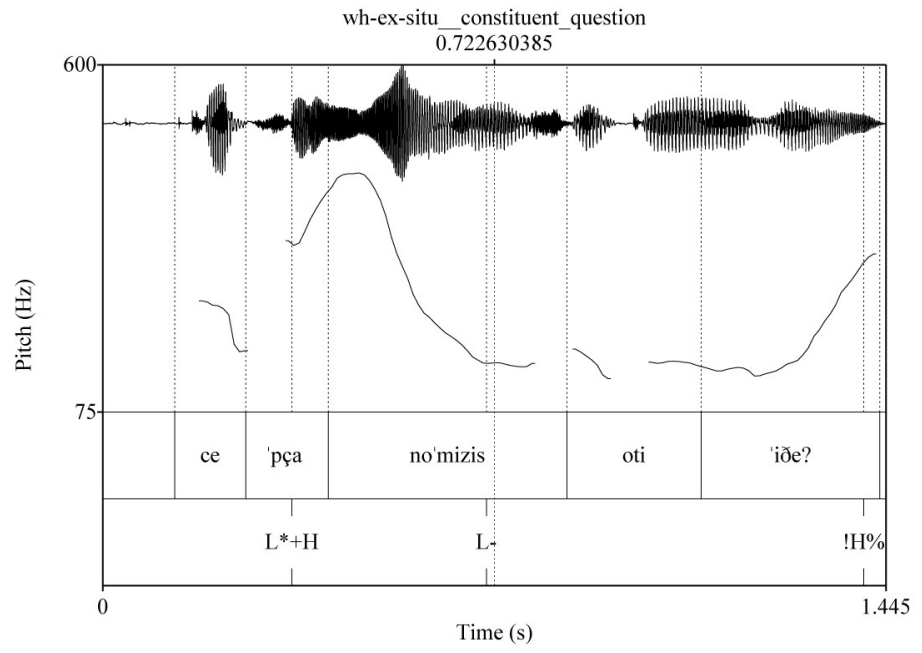

As we may observe in (11b), the pitch accent is $\mathrm{L}^{*}+\mathrm{H}$ (as the rising continues to the next syllable after the stressed one), the phrase accent is L-, which is realized on the next stressed syllable from pja 'who', and the boundary tone is ! $\mathrm{H} \%$, which falls on the last syllable of the utterance.

In a more recent experimental study on the intonation (and intonational meaning) of wh-fronting questions in Greek, Baltazani, Gryllia \& Arvaniti 
(2019) show that, instead of a high-ending tune, wh-fronting questions may carry a flat-ending melody. The high-ending intonation is typically associated with the 'question' meaning, while the flat-ending contour is not (or better, may not be). So, to paraphrase Baltazani, Gryllia and Arvaniti in a way that is consistent with the experimental findings of previous studies, we could say that when a $w h$-fronting construction yields a 'question' reading, the relevant melody is high-ending.

Vlachos's (2012) study shows that $w$ h-in situ questions fit the same intonational pattern, but with a crucial difference, to which we turn shortly. More in particular, the pattern is that the $w h$-in situ phrase has the same 'question' melody as its $w h$-fronting counterpart. This is demonstrated in (12b), which is the intonation contour of the $w h$-in situ question (12a).

(12) a. Ke nomizis oti idhe pja?

and think.2SG that saw.3SG who.ACC

'And you think that s/he saw who?'

b.

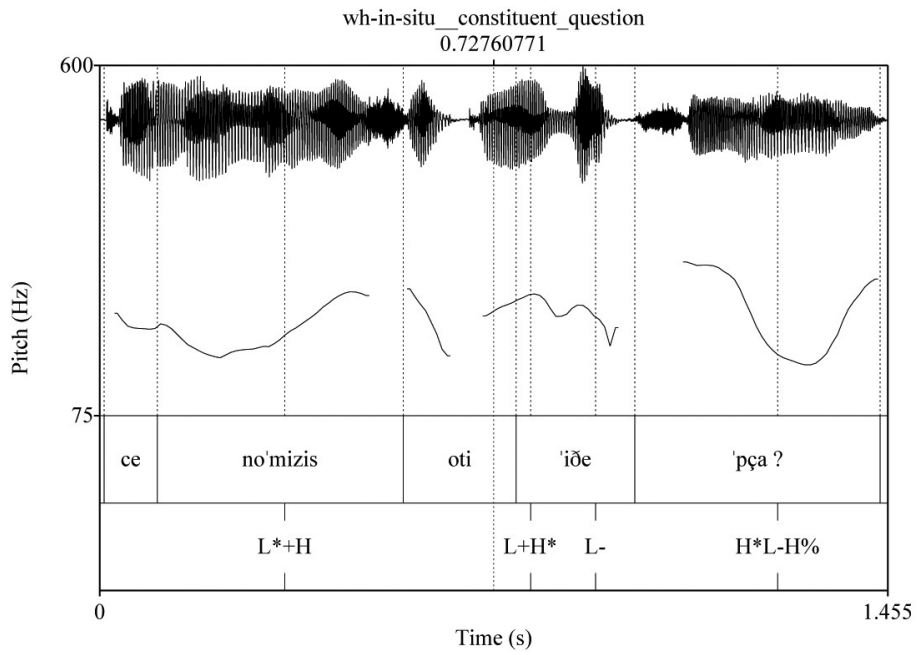

As we may observe in (12b), the melody of pja 'who', at the right of the utterance, is typical of $w h$-fronting questions, that is $\mathrm{H}^{*} \mathrm{~L}-\mathrm{H} \%$. Regarding the part of the utterance that precedes pja 'who', i.e., ke nomizis oti idhe 'and you think that $\mathrm{s} / \mathrm{he}$ saw', it is reasonable to argue that it constructs as an intermediate intonation phrase with two pitch accents, that is, $\mathrm{L}^{*}+\mathrm{H} \& \mathrm{~L}+\mathrm{H}^{*}$, and a L-phrase accent. The most important phonetic cue in favour of the hypothesis that the preceding part is an intermediate intonation phrase is the pitch gap of more than $100 \mathrm{~Hz}$ between the end of the intonation contour of the pre- 
ceding part and the beginning of the wh-element. It could also be noted that the preceding intermediate intonation phrase presents a typical intonation contour of the pre-focus element (see also Roussou, Vlachos \& Papazachariou 2013).

Now, the striking difference between the intonation contour of $w h$-fronting and in situ questions is the way it manifests on each utterance: in a $w h$-fronting question (cf., (12b)), the entire utterance is part of the 'question' melody, while in a $w h$-in situ question (cf., (12b)), the 'question' tune falls entirely on the $w h$ phrase, excluding the rest of the utterance (whose melody is described above). This difference becomes important in Section 4, where intonational meaning, and more precisely the interface between $\mathrm{PF}$ and pragmatics, is considered in more detail.

Before we end this section, it is worth mentioning that, like a $w h$-fronting question (see the discussion above), a $w h$-in situ question may alternatively be associated with a flat-ending intonation, as Alexopoulou \& Baltazani (2012) show. Yet, in a way similar to a $w h$-fronting question with a flat-ending tune, a $w h$-in situ question with a flat-ending melody yields a 'declarative' (and not a 'question') reading, in Alexopoulou \& Baltazani's (2012) terms. In other words, we take this evidence to mean that when a $w h$-in situ construction bears a 'question' reading, this reading maps to a high-ending contour.

Finally, let us turn to some aspects of the interpretation of $w h$-in situ questions, in comparison with that of their wh-fronting counterparts.

\subsection{Interpretation}

A striking difference in interpretation between $w h$-fronting and in situ questions concerns so called 'out-of-the-blue' environments, like (13). ${ }^{2}$

(13) a. Ja, ti jinete?

$\mathrm{Hi}$ what is-happening

'Hi, what's going on?'

b. \#Ja, jinete ti?

Hi is-happening what

'Hi, what's happening?'

2 For clarity, let us note that with the term 'interpretation' we refer more broadly to pragmatically induced meaning, which we distinguish from the syntactically computed meaning typically described with the term 'semantics'. 
As we may observe, the presence of the salutation element ja 'hi', at the beginning of the utterance, forces an out-of-the-blue context. The $w h$-fronting question in (13a) is felicitous in this context, but the $w h$-in situ counterpart is not (cf., (13b)).

$W h$-in situ questions become felicitous only if they are anchored to a 'discourse' (in the sense intended here, 'immediate linguistic environment'). For instance, consider the dialogue between two imaginary speakers A and $\mathrm{B}$ (the dialogue is adopted from Uribe-Etxebarria 2002: 222, (14a,b); see Vlachos 2012 for a first adaptation of this dialogue into Greek $w h$-in situ questions):

(14) a. Speaker A:

My father, my mother and I went to the store to buy eggs, milk and coffee. My mother bought the eggs.

b. Speaker B:

Ke o pateras su aghorase ti?

And the.NOM father.NOM yours bought.3sg what

'And your father bought what?'

In (14a), speaker A describes an event of buying that involves three agents, i.e., the speaker's father, mother and the speaker herself, as well as, three entities, i.e., eggs, milk and coffee. Speaker B, who is familiarized with the sets of agents and entities, by virtue of (14a), may address the $w$ h-in situ question in (14b). In other words, the value of the in situ $t i$ 'what' ranges over the set of entities already present in the discourse (with the exclusion of the entity eggs for obvious reasons).

Corroborating evidence that $w h$-in situ must be anchored to the discourse in a way that $w h$-fronting need not be comes from the observation that $w h$-in situ questions always assume the presence of a conjunctive $k e$ 'and', while $w h$ fronting questions may do so (see Vlachos 2019 for a first discussion). Witness (15) and (16).

(15) a. Speaker A:

Pigha ja psonia.

Went.1sG for shopping

'I went shopping.'

b. Speaker B:

(i) *(Ke) aghorases ti?

And bought.2SG what

‘*(And) you bought what?' 
(ii) (Ke) ti aghorases?

And what bought.2SG

'(And) what did you buy?'

Speaker B may follow speaker's A statement (cf., (15a)) with a wh-question (cf., $(15 \mathrm{~b}))$. In case of a $w h$-in situ question (cf., $(15 \mathrm{~b}-\mathrm{i})), k e$ 'and' must be present, but if the question is a $w h$-fronting one (cf., ( $15 \mathrm{~b}$-ii)), ke need not be present.

The fact that $k e$ 'anchors' the $w h$-question to the discourse comes from the observation that $k e$ renders out-of-the-blue $w h$-fronting questions, which resist discourse-anchoring (by definition), totally unacceptable, as in (16).

(16) \#Ke ti jinete?

And what is-happening

'\#And what's going on?'

In comparison with the felicitous (15b-ii), (16) says that a $w$ h-fronting question may be introduced by the conjunctive marker $k e$ as long as the utterance is tied to the discourse. On the other hand, the ungrammaticality of (15b-i) suggests that $w h$-in situ questions are always associated with the discourse, which is why we coincide with Vlachos' (2019) proposal that ke is always present in $w h$-in situ questions, either phonetically realized or not.

Considering further the interpretation of $k e$ in $w h$-in situ questions, Vlachos (2019) draws from Canakis' (1995) examination of the different senses of $k e$, and argues that, in $w h$-in situ questions, ke bears a 'while' reading, which may come in two senses: 'temporal' and/or 'adversative'. Refining Vlachos' (2019) observation, we say 'and/or' because, depending on the discourse, the two senses may be distinguished, in that one of the two surfaces while the other is nullified. This is obvious in (17), with the temporal sense prevailing over the adversative one.

(17) a. Speaker $A$

Fighame apo to spiti.

Left.3PL from the house

'We left home.'

b. Speaker B:

Ke pighate pu?

and went.3PL where

'And you went where?' (Vlachos 2019: 1018, (16)) 
The events denoted by the set of (true) propositions discharged by speaker's B question (cf., (17b)) temporally follow the event denoted by speaker's A statement (cf., (17a)).

Yet, there are cases where both senses may be available, as in (18) (fashioned from Vlachos 2019: 1019, (17)).

(18) a. Speaker A:

I Maria xoreve me ton Kosta.

the.NOM Maria.NOM was-dancing.3SG with the Kostas

'Maria was dancing with Kostas'.

b. Speaker B:

$\mathrm{Ke} i \quad$ Eleni xoreve me pjon?

and the.Nom Helen.Nom was-dancing with whom

'And Helen was dancing with whom'.

In one sense, the set of propositions denoted by speaker's B question (cf., (18b)) describe an event of dancing that takes place simultaneously with the event of dancing denoted by speaker A's statement (cf., (18a)). In another sense, the event denoted by speaker B's question is opposed to that of speaker A's statement (having an 'in contrast' reading). In the latter sense, the two events need not happen simultaneously, although they may do so. In passing, let us note that it may come as no surprise that the two senses may collapse, as in (18), if we consider the lexical semantics of 'while', which may have either a temporal or an adversative reading (see Vlachos 2019 for discussion).

The discussion about interpretation concludes the examination of the empirical evidence. Before we move on to the next sections, let us draw attention to the properties that the facts allude to, in a way that underpins the distinct stages of the analysis to follow. The evidence from distribution says that the structural position of a $w h$-in situ phrase is clearly distinct from that of a wh-fronting phrase. In fact, considerations regarding word order, embedding, islandhood and scope suggest that, contrary to $w h$-fronting, $w$ h-in situ must surface quite 'low' in the structure. The evidence from intonation supports this pattern: $w h$-in situ, despite featuring the same 'question' melody as $w h$ fronting, realizes the relevant tune differently, which presumably follows from the different structural positions that the two phrases surface at. The evidence from interpretation completes this pattern by showing that the different structural position of $w h$-in situ comes with a difference in meaning (along with a difference in intonation): unlike $w h$-fronting, $w h$-in situ is always discourseanchored, necessarily assuming the conjunctive marker $k e$ 'and'; this means 
that ke must be somehow implicated in the structure of $w h$-in situ, in a way that need not be present in the structure of $w h$-fronting.

In what follows, we derive the various properties of $w h$-in situ questions, in comparison with their $w h$-fronting counterparts, from the way syntax interacts with semantics and pragmatics. Placing the relevant properties at the interfaces, we begin with the syntax-semantics mapping (Section 3) and then we turn to the association between syntax and pragmatics (Section 4). We end the discussion with an effect we observe that intonation appears to have on the pragmatics of $w h$-in situ, which we attribute to the PF-pragmatics interface (Section 5).

\section{Syntax-semantics interface}

As is clear from the evidence presented so far, $w h$-fronting and $w h$-in situ are both available in Greek grammar. Our native speaker's intuition says that whfronting is the default, so to speak, strategy of the grammar. But intuition aside, we argue that two empirical observations strongly suggests that $w h$-fronting is the default strategy. One observation concerns syntax: $w h$-fronting is the only strategy that satisfies the selectional requirements of interrogative predicates (see Section 2.1). ${ }^{3}$ In non-technical terms, this observation means that whenever a question is required to complete the meaning of a predicate that selects questions, this question must be in the form of $w h$-fronting. The other observation is tied to pragmatics: $w h$-fronting is the only suitable strategy in contexts where no discourse is available ('out-of-the-blue'; see Section 2.3). In non-technical terms again, this observation means that whenever a 'question' begins a discussion from scratch, this 'question' must come in the form of $w h$-fronting. The fact that $w h$-fronting is the default strategy leads to the conclusion that $w h$-in situ is not just an 'optional' strategy, in that, the latter is not semantically equivalent to the former (or, vice versa, for that matter). On the typical assumption that syntax feeds semantics, the non-optionality of $w h$-in situ means that its syntax is distinct from the syntax of $w h$-fronting (see Vlachos 2019 for the same argument, framed within the relevant theoretical background). Let us consider this syntax.

3 This appears to be a pervasive property of $w h$-in situ across typically $w h$-fronting languages (see Bobaljik \& Wurmbrand 2015). We say "appears" because some Northern Italian varieties do not seem to fit this pattern, as they permit $w$ h-in situ without a phonetically realized complementizer in selected contexts (see Manzini \& Savoia 2011). 
As a first step toward a syntactic analysis of Greek $w h$-in situ, let us show how wh-fronting is formed, concentrating only on the part of the derivation that is relevant to our discussion. To this end, consider the English example in (19), which is enough to illustrate the relevant syntax.

\section{(19) [C Which student did [ ${ }_{\mathrm{T}}$ you (did) [v/v see $\langle$ which student $\left.\rangle\right]$}

The typical treatment of $w h$-fronting is in Chomsky (2000) and later publications. As in (19), which student (externally) merges in the predicate/V-domain (for simplicity, we collapse the vP-shell), where it acquires a $\vartheta$-role by being construed as the internal argument of see. The $w h$-phrase bears an interpretable $i \mathrm{Q}$ feature, while $\mathrm{C}$ comes with an uninterpretable $u \mathrm{Q}$ feature, and a (generalized) EPP feature (not indicated in (19)). C probes for and agrees with the wh-element, which acts as a Goal, valuing C's $u$ Q. Due to C's EPP, the whphrase moves (internally merges) to [Spec,CP], leaving a copy in its argument position. At LF, the copy (which is deleted at PF, by virtue of being a 'copy') translates to a 'variable' (via Fox's 1999 Trace Conversion mechanism), while the left-dislocated element is an operator ( $\lambda$-abstractor) that binds (abstracts over) the variable in the argument position (see Heim \& Kratzer 1998 for details). In short, $w h$-fronting assumes association with an interrogative $\mathrm{C}$, which triggers wh-movement (observed at PF), and operator-variable formation (available at $\mathrm{LF})$.

Within this frame, and specifically on the assumption that EPP triggers dislocation of the $w h$-phrase, it would be tempting to attribute $w h$-in situ to the lack of EPP for C. ${ }^{4}$ However, there are two reasons to disfavour this analysis for Greek. One reason is that such analysis would treat $w h$-in situ as truly 'optional', tying it to the 'optional' presence of EPP on C. But we have seen that $w$ h-in situ in not semantically equivalent to $w h$-fronting. The second reason, related to the first one, is that such analysis would associate $w h$-in situ with an interrogative $\mathrm{C}$ under long-distance agree. But the empirical evidence we have examined strongly suggests that $w$-in situ is not associated with an interrogative C. More precisely, as we may recall from Section 2.1, we have seen that $w h$-in situ does not satisfy the selectional requirements of an interrogative predicate. In more technical terms, this means that $\mathrm{C}$, which introduces $w h$-in situ, bears no $\mathrm{Q}$ feature, because if it did, selection by an interrogative predicate would lead to a grammatical result (contrary to facts). Supporting evidence that $\mathrm{C}$ in $w h$-in

4 In fact, this analysis has been proposed by Manzini \& Savoia (2011) for 'optional' $w h$-in situ in Northern Italian varieties. 
situ is not interrogative comes from the fact that, as we saw, a $w h$-in situ question can be the complement of both rogative and uninterrogative predicates, as long as $\mathrm{C}$ in $w h$-in situ is phonetically realized with an appropriate complementizer. Another observation that $w h$-in situ is not associated with $\mathrm{C}$ comes from scope considerations. The fact that, unlike $w h$-fronting, $w h$-in situ does not take scope over the entire proposition-i.e., its scope is restricted to the event of the clause, and cannot assume the entire fact - means that wh-in situ is not linked to $\mathrm{C}$, on the typical assumption that association with $\mathrm{C}$ is what grants 'propositional' scope to a $w h$-phrase (as in $w h$-fronting).

In conjunction with the word order and islandhood facts, which show that wh-in situ does not move (at least not as far as C), the most straightforward assumption to make is that a typical $w h$-in situ question in Greek, like (20a) (repeated from $(1 b))$, is derived as in $(20 b)$.

(20) a. Idhes pjon?

saw.3SG who.ACC

'You saw who?'

b.

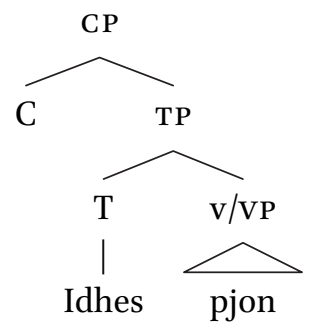

The schema in (2ob) says that $w$ h-in situ resides in its argument position, while C lacks both $u Q$ and EPP. Following Vlachos (2019), we maintain that whelements in Greek contain an interpretable $i \mathrm{Q}$ feature, so (20) translates at $\mathrm{LF}$ to a 'question.' 5

Let us, further, elaborate on the feature-specification of $\mathrm{C}$ in $w h$-in situ. More recently, in discussing English 'optional' wh-in situ, Bobaljik \& Wurmbrand

5 To be fair, the 'question' semantics of $w h$-in situ is not as straightforward as we take it to be. The issue is where the meaning of the 'question' comes from, if not from C (as is typically the case with $w h$-fronting). A related problem is how to interpret the $w h$-quantifier 'in situ'. We leave a detail treatment of the 'question' semantics of $w h$-in situ to future research as it requires an in-depth investigation of the semantic type of $w h$-elements, which is a non-trivial matter, and goes far beyond the scope of the present paper (as it would also require examination of contexts where a $w h$-phrase does not translate, strictly speaking, to a 'question', as in 'echoes' or 'exclamatives'). 
(2015) argue that C is 'declarative', an assumption also made by Sinopoulou (2009) for Greek $w h$-in situ. However, the empirical evidence from embedding we show in Section 2.1 suggests otherwise. Consider again (5), repeated as (21) for convenience.

(21) a. Pistevis oti ipe ti? believe.2SG that said.3SG what 'You believe that s/he said what?'

b. Dhen kseris an/oti ipe ti? NEG know.2SG if/that said.3SG what 'You don't know if/that s/he said what?'

c. Rotises an ipe ti? ask.2SG if said.3SG what 'You asked if s/he said what?'

If $\mathrm{C}$ in $w h$-in situ was 'declarative', (21b) and (21c) would be ungrammatical, contrary to facts, on the assumption that 'declarative' and 'interrogative' properties cannot collapse on the same C-head (see Rizzi 199o). In short, (21) clearly says that $w h$-in situ does not impose any preference on (the embedded) C, which can turn out to surface in the guise required by the matrix predicate.

By way of summary, let us briefly review the empirical facts from Section 2.1 through the schema in (20). In principle, (20) predicts that $w h$-in situ does not (and cannot, after all) exhibit the properties induced by $w h$-movement, i.e., vs word order, satisfaction of selectional properties of a matrix predicate, island violations, and propositional scope. What is more, (20) says that a wh-in situ question can be in the complement of any clause-selecting predicate, as long as selection is encoded on the embedded $C$ with a suitable complementizer.

The schema in (20) does not explain yet the obligatory anchoring of $w h$-in situ to the discourse. This is the issue we turn to next, delving more deeply into the interface of syntax with pragmatics. This will lead to a slight modification of $(20)$ in relevant respects.

\section{Syntax-pragmatics interface}

As has been pointed out in the discussion so far (see Section 2.3), wh-in situ questions always assume the presence of a conjunctive ke 'and', while whfronting questions may take that as an option. This empirical fact comes along 
with the observation that the presence of $k e$ coincides with the need for ' $\mathrm{D}$ (iscourse)-linking' (e.g., Pesetsky 1987) of $w h$-questions: On the one hand, $w h$-in situ questions are always D-linked, so they are always accompanied by ke. On the other hand, $k e$ is not available in out-of-the-blue wh-fronting questions. By way of illustration let us construct the following context. Imagine speaker A walking past a bus stop and asking a person waiting there (22).

(22) Speaker A:

Sighnomi, ti ora erxete to leoforio?

excuse-me what time comes.3sG the.NOM bus.NOM

'Excuse me, what time does the bus arrive?'

Assuming that the interlocutors are not related, question (22) is not linked to anything since there is no discourse constructed, therefore it comes out-of-theblue. It also follows that questions like these do not presuppose a possible set of answers.

In a setting like the one just described, questions (23) and (24) are not acceptable.

(23) Speaker A:

\#Ke ti ora erxete to leoforio?

and what time comes.3SG the.NOM bus.NOM

'And what time does the bus arrive?'

(24) Speaker A:

\#Ke to leoforio erxete ti ora?

and the.NOM bus.NOM comes.3sG what time

'And what time does the bus arrive?'

The presence of $k e$ requires that these questions must be discourse linked, and therefore in the absence of any particular discourse they are rendered infelicitous.

By contrast, if the question in (23) and (24) are accompanied by preceding discourse, they become perfectly acceptable. Consider the dialogue in (25).

(25) a. Speaker A:

To leoforio ksekinise apo tin afetiria ikosi lepta prin. the bus started from the terminal twenty minutes ago 'The bus left the terminal twenty minutes ago.' 
b. Speaker B:

Ke erxete ti ora?

and comes what time

'And what time does it arrive?'

In (25), an out-of-the-blue question like the one in (22) is not acceptable since in this case there is some information presupposed between the interlocutors. In passing, notice also that, apart from the $w h$-in situ, a $w h$-fronting question with the presence of $k e$ would also be felicitous.

In the light of the above discussion, we argue that ke is not used in the narrow conjunction sense, but receives an enriched discourse-pragmatic interpretation. More accurately, $k e$ functions as a discourse marker (DM) marking the conversational continuity and expressing the relation or relevance of the content of the question to the preceding context. A co-operative conversation normally takes place in a shared context, is highly interactive, is typically being co-constructed by the speaker and the hearer and involves dynamic and unplanned turn-takings as well as addressing questions. The role of DM is to indicate that there is a connection between some aspect of the discourse segment the DM is part of and some aspect of a prior discourse segment (Fraser 1999).

A way forward is to propose that $k e$, qua DM, establishes the common ground (à la Stalnaker 1978; Pires \& Taylor 2007) which is shared between interlocutors. Common ground is defined in Pires \& Taylor (2007) as information that was previously given in the discourse or the extralinguistic context, and which is shared (or assumed by the speaker to be shared) by speaker and hearer. Therefore, in cases like (25), the utterance made by speaker A constructs an informational context, i.e., a common ground, between the interlocutors, and this makes available a set of possible answers for speaker B's question. Ke marks the discourse by indicating that speaker B's wh-question is linked to speaker A's utterance and can be glossed as in (26) (in italics).

(26) a. Speaker A:

To leoforio ksekinise apo tin afetiria ikosi lepta prin. the bus started from the terminal twenty minutes ago 'The bus left the terminal twenty minutes ago.'

b. Speaker B:

Ke (afou ksekinise apo tin afetiria ikosi lepta prin) erxete ti ora?

'And (since the bus left the terminal twenty minutes ago) what time does it arrive?' 
The systematic co-relation between the presence of the marker ke and the discourse linking of $w h$-questions is elegantly explained if we assume that $k e$ projects in the structure of $w h$-in situ and is thus computed at the syntaxpragmatics interface. More precisely, drawing from approaches that "syntactisize the discourse" (e.g., Speas \& Tenny 2003; Haegeman \& Hill 2013), we propose that the syntax of $w$ h-in situ obligatorily features a speech act layer, as in (27), which completes the schema in (20).

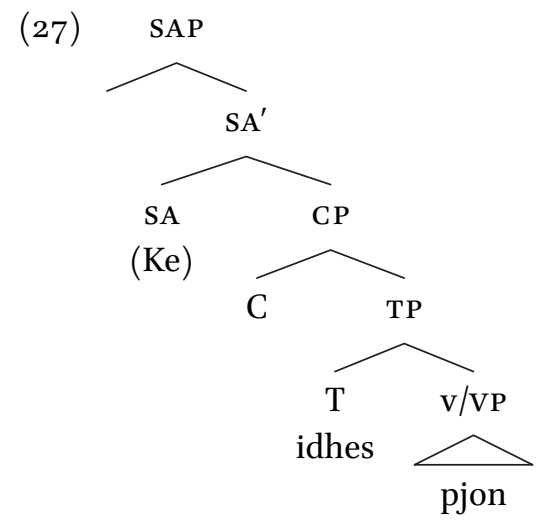

(27) encodes that a speech act layer projects on top of the C-periphery, and is headed by ke, which is either phonetical realized or not. This speech act layer is present in a $w h$-fronting question only if the latter is discourse-anchored; hence, optionally.

The schema in (27) captures the fact that ke anchors a $w h$-in situ question to the discourse. In the following section, we want to elaborate further on how this anchoring takes place, by concentrating on the way the two senses of $k e$, we observed in Section 2.3, interact with wh-in situ.

As we may recall from Section 2.3, ke bears a 'while' reading, which may come in two senses, 'temporal' and/or 'adversative'. While both senses may, in principle, become available (as we have already mentioned), we have the impression as native speakers that there is always a preference for the 'adversative' reading of $w h$-in situ. To describe this with an example, consider again the discourse in (14), repeated in (28) for convenience. 
(28) a. Speaker A:

My father, my mother and I went to the store to buy eggs, milk and coffee. My mother bought the eggs.

b. Speaker B:
Ke o
pateras
su
aghorase ti?
and the.NOM father.NOM yours bought.3sg what
'And your father bought what?'

The linguistic context in (28a) makes available a set of alternative values. Crucially, the $w h$-in situ question in (28b), in drawing a value from this set, seems to 'exclude' the other values of the set. That is, the reading seems to be 'butyour father bought what?' (a point first made in Vlachos 2012). So, along with their Dlinking, wh-in situ questions appear to prefer an 'adversative' reading. Drawing from Chiou \& Vlachos (2017), we want to tie this preference for the 'adversative' reading to the way the intonation of $w h$-in situ, given in Section 2.2, interacts with the pragmatics of $k e$.

More precisely, Chiou \& Vlachos (2017) (see also Vlachos 2014), assuming the analysis of Vergnaud \& Zubizarreta (2005), argue that the LF of a wh-question carries both a presupposition and a focus, which is captured as a(n) (iterative) disjunction between alternative propositions. So, the LF of $(28 \mathrm{~b})$ can be captured as in (29).

(29) (your father bought milk) on (your father bought coffee)

According to Vergnaud \& Zubizarreta (2005), OR may have either an 'inclusive' (indicated as ' $\mathrm{OR}^{i}$ ) or an 'exclusive' ( shown as ' $\mathrm{OR}^{c^{\prime}}$ ) reading, which is disambiguated via the corresponding $w$ h-question melody. Extending this system to Greek wh-questions, and revisiting Vlachos' (2014) relevant account, Chiou \& Vlachos (2017) argue that wh-in situ has an 'exclusive' interpretation on the grounds of the way the relevant intonation interacts with the pragmatics of $w h$ in situ. Refining (and simplifying somewhat) Chiou \& Vlachos' (2017) proposal, we want to tie the 'adversative' reading of $w h$-in situ to the 'exclusive' interpretation of oR. To this end, after we briefly consider 'disjunction' in natural language (Section 5.1), we turn to Grice's Maxims (Section 5.2), which we then apply to the intonational meaning of $w h$-in situ by way of a scalar implicature (Section 5.3).

\subsection{Disjunction}

In natural languages, the connective o $\mathrm{R}$ appears to be different from the semantics of disjunction in logic, in the sense that the former appears ambiguous 
between two main readings: the inclusive reading (as $p$ or $q$ or both) and the exclusive one (as $p$ or q but not both). By way of illustration consider the examples in (30).

(30) a. An applicant should have a degree in engineering or five years of programming experience.

b. John is a TV presenter or a physicist.

In (3oa), an applicant is fine if $\mathrm{s} / \mathrm{he}$ has both a degree in engineering and five years of programming experience and therefore, the inclusive reading is favoured. By contrast, in (3ob), the exclusive reading will be preferred since $p$ and $q$ are usually not both true.

The question whether to interpret $\mathrm{OR}$ as lexically ambiguous or not is a longstanding issue in the literature, not only in linguistics but also in logic (see, e.g., Smith 2012). Given the modified Occam's Razor according to which senses are not to be multiplied beyond necessity, Grice (1978) proposes an alternative to the ambiguity claim. Specifically, the two senses of or can be accounted for if we assume one basic interpretation and then derive all other readings by means of pragmatic inferences. Following this, the sense of OR is considered univocal and inclusive ( $p$ or $q$ or both); so the inclusive interpretation is the basic one. The exclusive reading ( $p$ or q but not both) is not part of the propositional content but is derived pragmatically by a conversational implicature. Let us consider the relevant framework in more detail in the following section.

\subsection{Gricean maxims and scalar implicature}

Grice builds his theory on the supposition that conversation moves along certain guidelines and assumptions. As Grice (1975: 45) states, "our talk exchanges do not normally consist of a succession of disconnected remarks ... they are, to some degree at least, co-operative efforts". Moreover, this cooperativeness is assumed for both the speaker and the hearer in a reciprocal manner. On these grounds, the theory of conversational implicature includes an overarching principle which Grice dubs the "cooperative principle". The cooperative principle of communication is defined in Grice (1975:45) along the following lines:

The cooperative principle:

Make your conversational contribution such as is required at the stage at which it occurs, by the accepted purpose or direction of the talk exchange in which you are engaged.

GRICE 1989: 26 
The cooperative principle is further subdivided into four conversational maxims and eight sub-maxims. According to Grice, the maxims along with the cooperative principle regulate efficient language use in communication:

The Gricean maxims of conversation:

Quality: Try to make your contribution one that is true.

(i) Do not say what you believe to be false.

(ii) Do not say that for which you lack adequate evidence. Quantity:

(i) Make your contribution as informative as is required (for the current purposes of the exchange).

(ii) Do not make your contribution more informative than is required. Relation: Be relevant.

Manner: Be perspicuous.

(i) Avoid obscurity of expression.

(ii) Avoid ambiguity.

(iii) Be brief (avoid unnecessary prolixity).

(iv) Be orderly. GRICE 1989: 26-27

The part of the Gricean maxims of conversation that is most relevant for our discussion is quantity implicatures. Quantity implicatures are triggered by the exploitation of the Gricean maxim of quantity and they are negative inferences in the sense that they refer to something that could have been said but was not said. Consider (31).

(31) A: Did Einstein propose General Relativity and the Exclusion Principle? B: Well, Einstein proposed General Relativity Implicature: Einstein did not propose the Exclusion Principle

In (31), B implies that the answer to A's question is not both. In this way she communicates the negation of A's statement implicitly.

A special case of quantity implicatures is scalar implicature. Particular linguistic expressions form entailment scales that are ordered in terms of the informational strength of utterances that contain them. A classic scale of this kind is quantifiers $\langle$ all, some $\rangle$. In such a scale, the semantic entailment has one direction making sure that the item to the left of the scale is informationally stronger than the item to the right (for more, see Horn 1989; Levinson 2000; among others). (32) demonstrates. 
(32) Some of Einstein's predictions are wrong

Implicature: not all of Einstein's predictions are wrong

Given the first maxim of quantity, in (32), the use of an utterance containing the informationally weaker term 'some', where an alternative proposition containing the informationally stronger term 'all' could have used, will trigger a quantity implicature communicating that the stronger claim does not hold. The implicated meaning is based on the negative nature of the inference since if the speaker could have made the stronger claim, she would have done so.

Within this frame, connective 'or' is a typical case of a scalar item. In particular, 'or' forms an informativeness scale with 'and'. 'And' is semantically stronger and stands for logical conjunction $(\Lambda)$, while 'or' is semantically weaker and stands for logical disjunction $(v)$. Following the same rationale as in $\left(3^{2}\right)$, to say $p$ or $q$ will implicate $\neg(p$ and $q)$. In other words, the use of the informationally weaker term, where the informationally stronger could have been used, will conversationally implicate that the proposition including the stronger one does not hold. So, the apparent ambiguity of connective 'or' between the inclusive and the exclusive readings can be resolved by deriving the latter pragmatically by a conversational implicature. Specifically, the exclusive reading is a combination of the logical disjunction and the scalar implicature, namely, $p \vee q$ and $\neg(p \Lambda q)$ gives $p$ or $q$ but not both (see, also Levinson 1983, among others).

One last crucial issue relevant to scalar implicatures is that they do not arise in contexts where the implicature would not contribute to making the utterance more informative (Katsos \& Breheny 2010). Observe the question-answer pairs in (33) and (34).

(33) A: Who proposed the Exclusion Principle?

B: It was Pauli or Heisenberg.

(34) A: What reading would you suggest for the assignment?

B: Study Pauli or Heisenberg and you will be fine.

(33) introduces an upper-bound context in the sense that interlocutors are interested in the strongest information possible and therefore the inclusive reading ( $p$ or $q$ or both) is not enough. By contrast, the implicated exclusive reading ( $p$ or $q$ but not both) increases the amount of contextually relevant information communicated by the speaker. The exclusive interpretation of the connective 'or' is an upper-bounded interpretation. On the other hand, in (34), the basic interpretation of the scalar item (i.e. the inclusive one) is sufficient for addressing the discourse goal and consequently, the scalar implicature will 
not be triggered. Contexts where computing the scalar implicature would be redundant are named lower-bound contexts and the inclusive interpretation of the connective 'or' is a lower-bounded interpretation.

Within this frame, in the next section, we explore the possibility that the prosody 'sees' the pragmatics of the iterative disjunction between alternative propositions in $w h$-in situ questions.

\subsection{The intonational meaning of wh-in situ}

Assuming the implicature account on the disjunction between alternative propositions in $w h$-in situ, we argue that the interpretation of $w h$-in situ questions can be accounted for by the division of labour between intonation and pragmatics.

By using the relevant intonation when uttering a wh-question, a speaker reveals her communicative intentions in the following way. As one may recall from Section 2.2, while $w h$-fronting and in situ share the same 'question' melody, they differ as to how this melody falls on each utterance: in $w h$-fronting, the tune includes the entire utterance, but in $w h$-in situ, it concentrates on the $w h$ phrase. We argue that the way the 'question' tune falls on each utterance has a pragmatic effect: in a $w h$-fronting intonation, anything goes as an answer; therefore, the semantic interpretation of or ( $p$ or $q$ or even both) is relevant. On the contrary, by opting for a $w h$-in situ melody, the speaker communicates that the wh-element selects a member from a set of alternatives in the context; so, the semantic meaning of or is not informative enough. By assuming cooperative communication, a scalar implicature will be triggered inducing an upper-bounding interpretation ( $p$ or q but not both).

Let us illustrate the above pragmatic effect with examples, commencing from (35).

(35) a. Pjos dhiatipose ti theoria tis Genikis Sxetikotitas? who-NOM proposed-3sG the theory of General Relativity 'Who proposed General Relativity?'

b. $\mathrm{L}^{*}+\mathrm{H}\left(\right.$ or $\left.\mathrm{H}^{*}\right) \mathrm{L}-! \mathrm{H} \%$

Given that a $w h$-question is captured as a(n) (iterative) disjunction between alternative propositions, the LF of (35) can be glossed as in (36):

(36) LF: (the theory was introduced by X) $\mathrm{OR}^{\mathrm{i}}$ (the theory was introduced by $\mathrm{Y})$ 
In (36), the 'fronting' melody will not trigger the scalar implicature because, in this context, the LF reading of oR (which is inclusive) is more informative. The speaker, by using the relevant melody, intends to communicate that any answer is possible.

By contrast, consider the scenario in which Lucy and Sandra want to go for a city break on the weekend but they have no idea as to where to go. Lucy says that she has been advised by a travel agency to visit Rome, London, and Madrid. Then Sandra asks (37):

\section{a. Ke tha pame pu? and will go-3PL where 'And, where are we going?'}

\section{b. $\mathrm{H}^{*} \mathrm{~L}-\mathrm{H} \%$}

Again, the LF of the question above contains an inclusive disjunction as in (38a). Nevertheless, what is actually communicated is the proposition in ( $38 \mathrm{~b})$.

(38) a. LF: (we will go at $X) \mathrm{OR}^{\mathrm{i}}$ (we will go at $\mathrm{Y}$ )

b. $L F$ : (we will go at $X) \mathrm{OR}^{\mathrm{c}}$ (we will go at $\mathrm{Y}$ )

Here, the 'in situ' melody triggers the scalar implicature because this implicature-driven interpretation of or is more informative, bearing context in mind. The speaker, by using the corresponding melody, intends to communicate that the $w h$-element selects a member from a set of alternatives in the context and hence an 'exclusive' ('adversative') reading is preferred.

The proposed implicature account, apart from explaining how the speaker reveals her communicative intentions by opting for the relevant intonation when uttering the question, also predicts that the role of context is critical in the interpretation of $w h$-questions (see also Baltazani, Gryllia \& Arvaniti 2019; Gryllia, Baltazani \& Arvaniti 2018, 2019). It can be argued that the absence of a potential answer in the context introduces a lower-bound context whereas the presence of a set of possible answers in the discourse introduces an upperbound context. As mentioned earlier in the discussion, scalar implicatures are generally triggered in upper-bound contexts since they convey the logically strongest information possible by increasing the amount of contextually relevant information communicated by the speaker. By contrast, in lower-bound contexts the semantic meaning is informative enough and hence a scalar implicature reading is not necessary. This, in turn, captures quite nicely the reason why $w h$-fronting questions are felicitous in aggressively non-D-linked (hence 
lower-bound) contexts, while $w h$-in situ questions are preferred in contexts where there are potential answers already established in the discourse.

\section{$6 \quad$ Conclusion}

This paper has examined the syntax, semantics and pragmatics of $w h$-in situ questions in Greek, in comparison with their $w h$-fronting counterparts. While $w h$-fronting is the default strategy of question-formation in Greek, wh-in situ is not an 'optional', that is, semantically alternative, strategy of $w$ h-fronting. Specifically, various distributional, prosodic and interpretational facts suggest that $w h$-in situ surfaces in the position it first merges (be it an argument or adjunct), is not associated with an interrogative Complementizer, and is obligatorily anchored to the discourse via the conjunctive marker $k e$ 'and'. In fact, $k e$ functions as a Discourse Marker, projecting in a Speech Act layer on top of the left periphery of $w h$-in situ.

\section{Acknowledgments}

Part of the discussion in this paper has been presented at the "Unbounded Seminars in Formal Linguistics" (University of Genève; June 2019) and part at the 14th International Conference on Greek Linguistics (University of Patras; September 2019). For helpful comments and suggestions, we are grateful to an audience at both venues, and especially to Amalia Arvaniti, Caterina Bonan, Costas Canakis, Renos Georgiou, George Kontzoglou, George Magionos, Vassilios Spyropoulos, and Evangelia Vlachou. Also, we would like to thank two anonymous reviewers for constructive criticism. Christos Vlachos gratefully acknowledges that research for this paper has been funded by the Hellenic Foundation for Research and Innovation (H.F.R.I.), through the University of Patras (Grant No. 23/806o2). All remaining errors are ours.

\section{References}

Alexopoulou, Theodora \& Mary Baltazani. 2012. Focus in Greek wh-questions. In: Contrasts and positions in information structure, ed. by I. Kucerova and A. Neeleman, 206-246. Cambridge: Cambridge University Press.

Arvaniti, Amalia \& Robert D. Ladd. 2oog. Greek wh-questions and the phonology of intonation. Phonology 26: 43-74. 
Arvaniti, Amalia. 2001. The intonation of wh-questions in Greek. Studies in Greek Linguistics 21: 57-68.

Baltazani, Mary, Stella Gryllia \& Amalia Arvaniti. 2019. The intonation and pragmatics of Greek wh-questions. Language and Speech, 1-39. [DoI: https://doi.org/10.1177/ oo23830918823236]

Bobaljik, Jonathan David \& Susi Wurmbrand. 2015. Questions with declarative syntax tell us what about selection. In: 50 Years Later: Reflections on Chomsky's Aspects, ed. by Gallego, J. Ángel \& Dennis Ott, 13-32. MIT Working Papers in Linguistics.

Canakis, Kostas. 1995. Kal: The story of a conjunction. University of Chicago, doctoral dissertation.

Chiou, Michalis \& Christos Vlachos. 2017. The pragmatics of $w h$-in situ questions in Greek. Studies in Greek Linguistics 37: 201-211.

Chomsky, Noam. 200o. Minimalist inquiries: The framework. In: Step by step: Essays on minimalist syntax in honor of Howard Lasnik, ed. by Roger Martin, David Michaels \& Juan Uriagereka, 89-156. Cambridge, MA: MIT Press.

Fox, Danny. 1999. Reconstruction, Binding Theory, and the interpretation of chains. Linguistic Inquiry 30 (2): 157-196.

Fraser, Bruce. 1999. What are discourse markers? Journal of Pragmatics 31: 931-953.

Giannakidou, Anastasia. 1998. Polarity sensitivity as (non)veridicality. Amsterdam: John Benjamins.

Grice, H. Paul. 1975. Logic and conversation. In: Syntax and semantics 3: Speech acts, ed. by Peter Cole \& Jerry L. Morgan, 41-58. New York: Academic Press.

Grice, H. Paul. 1978. Further notes on logic and conversation. In: Syntax and semantics 9: Pragmatics, ed. by Peter Cole, 113-128. New York: Academic Press.

Grice, H. Paul. 1989. Studies in the way of words. Cambridge, MA: Harvard University Press.

Gryllia, Stella, Mary Baltazani \& Amalia Arvaniti. 2018. The role of pragmatics and politeness in explaining prosodic variability. In: Proceedings of the gth International Conference on Speech Prosody, ed. by Klessa Katarzyna, Jolanta Bachan, Agnieszka Wagner, Maciej Karpiński \& Daniel Śledziński, 158-162. [DoI: https://doi.org/10.2143 7/SpeechProsody.2018-32]

Gryllia, Stella, Mary Baltazani \& Amalia Arvaniti. 2019. Evidence for the compositionality of intonational meaning. In: Proceedings of the 19th International Congress of Phonetic Sciences, ed. by Sasha Calhoun, Paola Escudero, Marija Tabain \& Paul Warren, 2841-2845. Canberra, Australia: Australasian Speech Science and Technology Association Inc.

Haegeman, Liliane \& Virginia Hill. 2013. The syntacticization of discourse. In: Syntax and its limits, ed. by Raffaella Folli, Christina Sevdali \& Robert Truswell, 370-39o. Oxford: Oxford University Press.

Heim, Irene \& Angelika Kratzer. 1998. Semantics in Generative Grammar. Oxford: Blackwell. 
Horn, Laurence. 1989. A natural history of negation. Chicago: University of Chicago Press.

Horrocks, Geoffrey \& Melita Stavrou. 1987. Bounding theory and Greek syntax: Evidence for wh-movement in NP. Journal of Linguistics 23: 79-108.

Katsos, Napoleon \& Richard Breheny. 2010. Two experiments and some conclusions on the meaning of scalars and numerals. In: The role of data at the semantics-pragmatics interface, ed. by E. Nemeth \& K. Bibok, 125-16o (Mouton Series in Pragmatics 8). Berlin \& New York: De Gruyter Mouton.

Kotzoglou, George. 2005. Wh-extraction and locality. University of Reading, doctoral dissertation.

Kotzoglou, George. 2006. Subject-verb inversion in Greek: Implications for head movement and typology. Journal of Universal Language 7: 91-137.

Lahiri, Utpal. 2002. Questions and answers in embedded contexts. Oxford: Oxford University Press.

Levinson, Stephen C. 1983. Pragmatics. Cambridge: Cambridge University Press.

Levinson, Stephen C. 200o. Presumptive meanings. Cambridge, MA: M Iт Press.

Manzini, M. Rita \& Leonardo M. Savoia. 2011. Wh-in situ and $w h$-doubling in Northern Italian varieties: Against Remnant Movement. Linguistics Analysis 37: 1-2.

Pesetsky, David. 1987. Wh-in situ: Movement and unselective binding. In: The representation of (in)definiteness, ed. by E. Reuland \& A. ter Meulen, 98-129. Cambridge, MA: MIT Press.

Pires, Acrisio \& Heather Taylor. 2007. The syntax of wh-in situ and Common Ground. Papers from the Annual Meeting of the Chicago Linguistic Society 43: 201-215.

Rizzi, Luigi. 1990. Relativized minimality. Cambridge, MA: MIT Press.

Ross, J. Robert. 1967. Constraints on variables in syntax. Cambridge, MA: MIT, doctoral dissertation.

Roussou, Anna, Christos Vlachos \& Dimitris Papazachariou. 2013. In situ, ex situ and (non-)echo questions. In: Major trends in theoretical and applied linguistics: Selected papers from the 2oth International Symposium on Theoretical and Applied Linguistics, vol. 3, ed. by Nikolaos Lavidas, Thomaï Alexiou \& Areti Maria Sougari, 475-494. London: de Gruyter.

Roussou, Anna. 2010. Selecting complementizers. Lingua 120: 582-6o3.

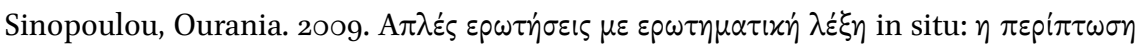

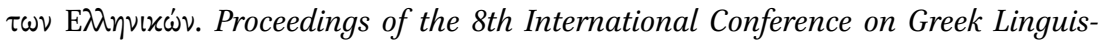
tics, Ioannina 30 August-2 September 2007, ed. by Mary Baltazani, Georgios Giannakis, George J. Xydopoulos \& Anastasios Tsangalidis, University of Ioannina, 11181132.

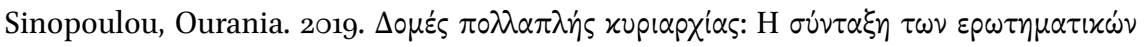

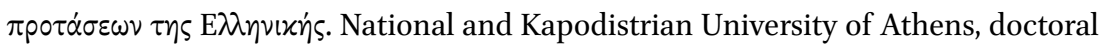
dissertation. 
Smith, Nicholas J.J. 2012. Logic: The Laws of Truth. Princeton, NJ: Princeton University Press.

Speas, Peggy \& Carol Tenny. 2003. Configurational properties of point of view roles. In: Asymmetry in grammar, Volume 1: Syntax and semantics, ed. by Anna Maria di Sciullo, 315-344. Amsterdam: John Benjamins.

Stalnaker Robert. 1978. Assertion. In: Syntax and semantics 9: Pragmatics, ed. by Peter Cole, 315-322. New York: Academic Press.

Starke, Michael. 2001. Move dissolves into merge: A theory of locality. University of Geneva, doctoral dissertation.

Szabolcsi, Anna. 20o6. Strong vs. weak islands. In: The Blackwell companion to syntax, ed. by M. Everaert \& H. van Riemsdijk, 479-531. London: Blackwell

Uribe-Etxebarria, Myriam. 2002. In situ questions and masked movement. Linguistic Variation Yearbook 2: 215-255.

Vergnaud, Jean-Roger \& Maria-Luisa Zubizarreta. 2005. The representation of focus and its implications: Towards an alternative account of some 'intervention effects'. Organizing grammar. Studies in honour of Henk van Riemsdijk, ed. by H. Boekhuis, N. Corver, R. Huybregts, U. Kleinhenz \& J. Koster, 641-678. Paris: Mouton De Gruyter.

Vlachos, Christos. 2010. Wh-in situ: The case of Greek. In: Movement and clitics: Adult and child grammar, ed. by V. Torrens, L. Escobar, A. Gavarró, and J. Gutiérrez, 84-111. Cambridge: Cambridge Scholars Publishing.

Vlachos, Christos. 2012. Wh-constructions and the division of labour between syntax and the interfaces. University of Patras, doctoral dissertation.

Vlachos, Christos. 2014. Wh-inquiries into Modern Greek and their theoretical import(ance). Journal of Greek Linguistics 14: 212-247.

Vlachos, Christos. 2019. False optionality: When the grammar does mind. Studies in Greek Linguistics 39:1013-1023. 